\title{
Prevalence of Colour Vision Deficiency (CVD) In Medical Students In Kolkata, West Bengal
}

\author{
Dipa Saha ${ }^{1}$, Kaushik Saha ${ }^{2}$ \\ ${ }^{1}$ MD, Associate Professor Of Physiology, Department Of Physiology, KPC Medical College And Hospital \\ Jadavpur, Kolkata, India. \\ ${ }^{2}$ MD, Associate Professor Of Medicine, Department Of Medicine, Malda Medical College, West Bengal, India.
}

\begin{abstract}
Objective: Colour vision is a function of three types of cone pigments present in retina. Any abnormality in the cone pigments may cause deficiency of colour vision which is called as colour blindness. The incidence of Colour vision deficiency varies from race to race and different in different geographical areas. Colour is very important sign used in medical profession, but there is no effective screening for Colour Vision Deficiency (CVD) at any level of medical profession. The present study was undertaken to find out CVD in medical students at different Medical Colleges in Kolkata.

Material and Method: A total of 300 medical students including 168 males and 132 females between 18-22 years were examined for CVD in Medical colleges in Kolkata. Each student without ocular abnormality was shown Ishihara's plates under day light at normal reading distance.

Results: Among 168 boys, 8 were colour deficient (4.8\%), and 46 (27.3\%) showed red-green anomaly. Among 132 girls, 46 (34.8\%) showed red-green anomaly.

Conclusions: With this incidence of colour vision deficiency, students with CVD may feel difficulty in day-today practice in medical field. So, screening for CVD in medical students and medical technicians at the time of selection is very important and that may help for early management of CVD.
\end{abstract}

Keywords: Ishihara's charts (plates), Colour vision deficiency (CVD), Medical students

\section{Introduction}

We all know that colour vision is the ability to discriminate a light stimulus as a function of its wavelength. Light with wavelength between approximately 380 and $760 \mathrm{~nm}$ causes photoreaction on human retina, which leads to vision. Various sensory and cognitive processes combine to result in the sense of colour. [1] In our health care system, colour vision has immense role. Colours have three attributes - hue, saturation and intensity [2]. Those who have colour vision defect are actually not blind persons.

The description and appreciation of colours depend upon the ability of receptors in retina i.e. rods and cones. Rods are mainly responsible for black and white vision whereas cone systems are mainly responsible for colour vision.

Scientific paper on CVD was published by John Dalton, who was himself colour blind [3]. CVD is the disturbance of colour perception that occurs due to reduced amount of visual pigment in cone cells [4]. CVD persons are unable to distinguish between different colours of spectrum. Colour vision deficiency represents a group of conditions that affects the perception of colour. Red-green colour vision defect is the most common form of CVD. CVD disrupt colour perception but do not affect the sharpness of vision or visual acuity.

Most common cause is a fault in development of one or more sets of retinal cones that perceive colour in light and transmit information to the optic nerve. Red, green and blue are three primary colours and colour is mediated by the ganglion cells that add inputs from one type of cones to others.

Normal persons are trichomatic, i.e. the 3 primary hues are detected by 3 types of cones. The persons discriminate colours by comparing the absorption of photon at different rates. When specific colour cone is missing, person is unable to distinguish same colour from others. We can classify CVD into four types - Protan (red defect), Deutan (green defect), Tritan (blue defect) and Achromatopsia (total absence of colour vision [5].

Colour vision defect may be congenital or acquired. Congenital defects are X-linked and acquired deficiencies are caused by ocular pathologies [6] and drugs [7].

Health professionals suffering from CVD have difficulty in identifying body colour changes, colour coded medicines, charts, slides, colour sensitive monitors. Colour is an important sign in medical profession, but there are very few studies with implication of CVD in medical professionals. Very few studies have been performed in this field.

Our study identifies the incidence of CVD in medical students, as screening for CVD is very important because it can affect doctors' day-to-day practice and early screening may help early intervention and management. 


\section{Materials And Methods}

Total 300 medical students of first year MBBS class has been studied. Of these, 168 boys and 132 girls aged between 19 - 22 years have been tested for CVD in Medical Colleges, Kolkata. The inclusion criteria were $1^{\text {st }}$ year MBBS without ocular anomaly.

Each student was shown the complete range of Ishihara's colour vision plates under day light.

The colour vision testing plates were held at $75 \mathrm{~cm}$ from the student and tilted at right angle to the line of vision. The test was done in adequate lighted room resembling natural day light. Student was asked to read the numbers seen on the test plates and answer was noted down. The time given for telling the number on a plate was less than $5 \mathrm{sec}$ [8]. Assessment of the reading of the plate determines the normality or defectiveness of colour vision and also the type of colour blindness. It was interpreted as per the instructions given on the booklet provided with Ishihara's type tests for colour blindness so as to identify subject suffering from colour blindness and also to differentiate the type of colour blindness. All the students were examined within two months duration.

As the students have joined medical colleges from different parts of the country, the study examines colour vision in medical students of not only West Bengal, but across a larger part of India.

\section{Results}

Total 300 students of age group 19-22 years were examined. The frequency of CVD in the subjects is shown in Table-1.

Table 1: Frequency distribution of CVD in first year medical students $(n=300)$ in Kolkata, West Bengal:

\begin{tabular}{|l|c|c|}
\hline \multicolumn{1}{|c|}{ Subject $(\mathbf{n}=\mathbf{3 0 0})$} & Number & Percentage \\
\hline Male $(\mathbf{n}=\mathbf{1 6 8})$ & 8 & $4.8 \%$ \\
\hline Female $(\mathbf{n}=\mathbf{1 3 2})$ & 0 & $0 \%$ \\
\hline
\end{tabular}

Table 2: Frequency distribution of Red-Green Colour Anomaly in first year medical students $(n=300)$ in Kolkata, West Bengal:

\begin{tabular}{|l|c|c|}
\hline \multicolumn{1}{|c|}{ Subject $(\mathbf{n}=\mathbf{3 0 0})$} & Number & Percentage \\
\hline Male $(\mathbf{n}=\mathbf{1 6 8})$ & 46 & $27.3 \%$ \\
\hline Female $(\mathbf{n}=\mathbf{1 3 2})$ & 46 & $34.8 \%$ \\
\hline
\end{tabular}

\section{Discussion}

CVD prevalence varies from country to country and even race to race. Vijayalakshmi et al, reported CVD in Hindu casts and religious groups of different parts of India. The prevalence reported was $2.1 \%$ in 7542 males and $0.2 \%$ in 3519 females [9]. In Western Nepal, in a study on 964 school children (10-19 years age group), CVD was found in 18 boys with prevalence of $3.8 \%$, but none of the girls was found affected [12]. In USA, prevalence of CVD in junior medical students was $12.8 \%$ [10]. In the present study, the observation among medical students of Medical colleges, Kolkata, W.B. revealed prevalence of $4.8 \%$ in males.

The prevalence of red-green colour anomaly among males was $27.3 \%$ and in females, $34.8 \%$. There is significantly higher prevalence of red green anomaly in females.

Studies showed, individuals with CVD and colour vision anomaly (red-green) perform less than those with normal colour vision.

CVD is very hazardous problem for certain groups of doctors examining pallor, cyanosis, erythema and certain range of colours that can cause failures of discrimination with CVD [6, 10, and 11].

\section{Conclusion}

The medical students suffering from CVD may feel difficulty in identifying colour slides, specimen and examining of certain physical signs. In many cases, colour blind students may remain undetected and student remains unaware about the disability. It may cause difficulties in various aspects of learning which then resulted into decrease in interest and lesser efficiency in work, preventing the student to reach up to his/her maximal potential. Screening for CVD and colour vision anomaly in medical students and medical technicians at the time of selection is very important. This may help in early detection and management of CVD more effectively. 


\section{References}

[1]. Park K. , Park's Textbook of Preventive and Social Medicine. 19th edition. Feb 2007. BanarasidasBhanot Publishers, Jabalpur, India. pp. 57.

[2]. Barret KE, Barman SM, Boitano S, Brooks HL. Vision, In: Ganong's Review of Medical Physiology. 23 ${ }^{\text {rd }}$ Edition. New Delhi: Tata McGraw Hill Education Private Limited; 2010. p.195-7

[3]. Dalton J. Extraordinary facts relating to the vision of colours: with observations. Memoirs of the Literary and Philosophical Society of Manchester 1798; 5:28-45

[4]. Colors for color blind. (Clinical information) 2011; Available at: http//www.teledo-blend.com/color blind/cbinfo.asp

[5]. Color blindness: genetics. Available at: http//www.buzzle.com/articles/colour-blindness-genetics.html

[6]. Splading JAB. Colorvison deficiency in medical profession. Br J Gen Prac 1999; 49(443): 469-75

[7]. Ruddock KH. Acquired deficiencies of human color vision. Bailliere's Clinical Neurology. London: Bailliere Tindal;1993

[8]. Balasundaram R, Reddy S C, Prevalence of colour vision deficiency among medical students and health personnel. Malaysian Family Physician, 2006; 1(2\&3): 52-53.

[9]. Vijayalakshmi M, Naidu JM, Suryanar. Blood group ABH Saliva secretions and colour vision deficiency in Hindu casts and religious group of West Godavari, Andhra Pradesh, India. Anthopolanz, 1994;52(4):305-13

[10]. Logan JS. The disability in so called red green colour blindness. An account based on many years of self-observation. Ulster Med J $1977 ; 46: 41-5$

[11]. Spalding JAB. Doctors with inherited colour vision deficiency: their difficulties in clinical work. In: Cavonius CR (Ed) Color vision deficiencies XII. Dordrecht, Kluwer Academic 1997; 20: 483-9

[12]. Niroula, Saba. The incidence of colour blindness among some school children of Pokhara, West Nepal. Nepal Med Coll J 2010;12(1):48-50. 